\title{
MULTIWIRE SUBMERGED ARC WELDING OF STEEL STRUCTURES
}

\author{
R. Dhollander ${ }^{1}$, S. Vancauwenberghe ${ }^{1}$ \\ W. De Waele ${ }^{2}$, N. Van Caenegem ${ }^{3}$ and E. Van Pottelberg ${ }^{4}$ \\ ${ }^{1}$ Ghent University, Belgium \\ ${ }^{2}$ Ghent University, Laboratory Soete, Belgium \\ ${ }^{3} \mathrm{BIL}$, Belgium \\ ${ }^{4}$ OCAS, Belgium
}

\begin{abstract}
The assembly of large structures made out of thick steel plates requires a welding process by which multiple wires can be used simultaneously. To reproduce these industrial processes in a research environment, OCAS has invested in a multiwire submerged arc welding (SAW) setup. In this multiwire setup, up to five wires in tandem configuration can be used.

The objective of this master thesis is to establish a deeper knowledge of process parameters used to weld steel plates in a thickness range of 12,7 up to $25 \mathrm{~mm}$, by means of the submerged arc welding process. Based on literature, a test matrix is composed in which the number of wires, the plate thickness and other weld parameters are the variables. In addition, a specific plate preparation for each plate thickness is derived from the literature. The preformed weld trails will be evaluated on weld bead geometry and metallographic properties. There is further experimental examination required, which will result in the revising of the matrix.
\end{abstract}

Keywords: Submerged arc welding; multiwire; parameters; weld bead geometry; plate preparation

\section{INTRODUCTION}

Submerged arc welding is used in the pipe manufacturing, windmill construction, in pressure vessel construction and in shipbuilding. Its welding procedure is characterized by the combination and interaction of multiple parameters: e.g. heat input, voltage, current, plate preparation and welding speed.

The goal of this master thesis is to establish a deeper knowledge of the submerged arc welding process. The first step is to study the available literature and to make assumptions for the welding parameters, based on reported successful experiments. This knowledge is used to compose a test matrix, which contains the main process parameters and can be used for practical weld trials on steel plates of grade S235. The quality of the weld will be inspected visually and via metallography. The outcome of these tests and evaluations will be used to develop welding procedures for steel S235 with different plate thicknesses. This feedback is used to adjust the welding procedures.

\subsection{Principle}

The principle of the submerged arc welding process is illustrated in Figure 1 for a single wire configuration.

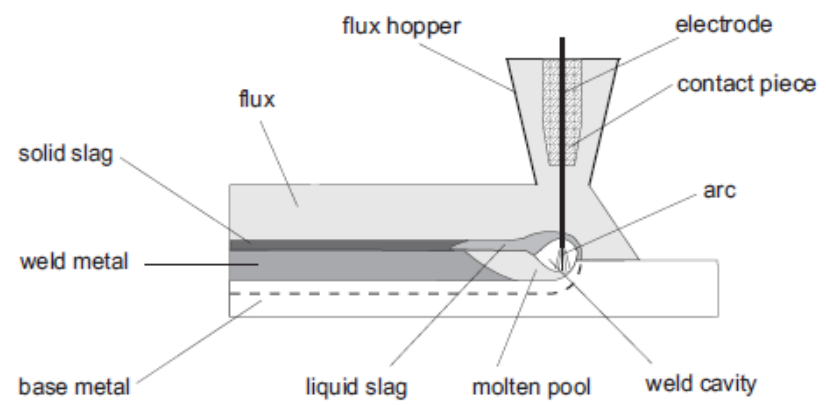

Figure 1: SAW process [1] 
First a layer of flux powder is added onto the weld preparation. The tip of the wire electrode is fed into the flux. The workpiece and the wire are on a different voltage level. This results in the formation of an arc. The arc conducts high currents, which lead to heat generation in the wire, flux and workpiece. The continuously supplied wire electrode melts off in the molten pool. The flux melts, adds a protective layer on top of the weld and promotes the slack layer peal off.

\subsection{Equipment}

The machine setup consists of a vertical beam which carries a movable horizontal beam. Along one side of the horizontal beam structure, an SAW-head is fitted, on the other side a MIG /MAG-torch. The number of welding wires that are lined up in series on the SAW-head, can be varied from one to five. The wires are powered by a DC power source (LAF 1601) for the first wire and a separate AC power source (TAF 1251) for each of the other wires.

In Table 1 an overview of the main machine dimensions is presented.

Table 1: Dimensions of the machine

\begin{tabular}{|c|c|c|c|}
\hline & $\begin{array}{c}\text { Machine } \\
\text { dimensions }\end{array}$ & $\begin{array}{c}\text { Maximum welding } \\
\text { area }\end{array}$ & Speed range \\
\hline Length & $17,5 \mathrm{~m}$ & $14 \mathrm{~m}$ & $0-4 \mathrm{~m} / \mathrm{min}$ \\
\hline Height & $7 \mathrm{~m}$ & $4,2 \mathrm{~m}$ & $0-3 \mathrm{~m} / \mathrm{min}$ \\
\hline Current & $1200 \mathrm{~A}$ & - & - \\
\hline Voltage & $50 \mathrm{~V}$ & - & - \\
\hline
\end{tabular}

\subsection{Advantages and disadvantages}

Several characteristics make this process interesting for industrial applications. The addition of flux covers the weld. No extra gasses are needed to protect the weld from environmental pollution. The welding spatters will be minimized and it protects the welder from UV-radiation [2]. Besides the heat loss is reduced, which leads to a high thermal efficiency $(\sim 95 \%)[3,4]$. A disadvantage of this flux cover is the need for automation because once started, no visible feedback is available [3]. The advantage of automation is a higher reliability, a higher quality of the weld and a greater comfort for the welder [2, 3, 5].

Compared to other welding processes, submerged arc welding delivers high welding speeds, melting rates and a deep penetration [6]. But the weld is restricted to few and easy accessible positions (PA, PB, PC) and from a practical and economical point of view, a minimum welding length is required, so a steady-state regime condition is reached over a certain length. Due to the higher melting rate and high heat input, crack formation will be more likely [7, 8].

\section{INFLUENCES ON WELD GEOMETRY AND PROPERTIES}

The weld bead geometry, metallurgy and mechanical properties of the weld depend on different, independently controllable process parameters. Their influence is not always clearly defined. Literature focuses on the influence of one or two parameters at a time. The determination of a general formula to predict the appearance and properties of a weld is almost impossible, because of the interaction effects of various parameters $[3,5,9,10]$.

\subsection{Definitions}

\subsubsection{Dilution}

Dilution is defined as the change in chemical composition of the weld metal, caused by the blending of the base metal and the wire electrode. It is determined by the ratio of the base metal melted (cfr. hatched area in Figure 2) to the total weldpool metal (cfr. area enclosed by the line in Figure 2) [11]. A dilution equal to 0,4 means that the fraction of weld metal that came from the consumable electrode is $60 \%$.

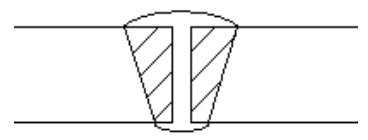

Figure 2: Dilution 


\subsubsection{Heat Input}

Heat input $(H I)$ quantifies the amount of heat that is injected into the weld bead during the welding process.

$$
H I=\frac{60 \mu \sum_{1}^{n}(V I)}{1000 S}
$$

Formula (1) gives an analytical expression for heat input and is expressed in $\mathrm{kJ} / \mathrm{mm}, \mu$ is the thermal efficiency of the process, $V$ is the arc voltage in volts, $n$ is the number of wire electrodes, $l$ is the welding current in ampere and $S$ is the welding speed in $\mathrm{mm} / \mathrm{min}[3,12,13]$.

\subsubsection{Arc blow}

Arc blow is the deflection of the arc, which means that the arc will not follow the shortest path between the wire electrode tip and the base metal. Deep weld preparations and the start/stop of the weld are more sensitive to this phenomenon. The causes can be magnetic or thermal. Magnetic interference occurs due to an asymmetry in the magnetic field around the arc. Thermal arc blow takes place because the current prefers a path between two hot regions, which causes the arc to hang back.

In multi-wire SAW, the first wire electrode is fed by a DC-source and the following wires are fed by AC. This results in a reduced risk of arc blow [7, 14].

\subsection{Variable parameters}

In Table 2 an overview, showing the influence of arc voltage, welding current and welding speed on different parameters is given.

Table 2: Variable parameters

\begin{tabular}{|c|c|c|c|}
\hline & Arc voltage $\lambda$ & Current $\lambda$ & Welding speed $\lambda$ \\
\hline Heat Input & $\lambda[15]$ & $\nearrow[8]$ & $\searrow[16]$ \\
\hline Excess weld metal & $\searrow[7]$ & $\nearrow[2]$ & $\searrow[16]$ \\
\hline Width of weld bead & $\lambda[7]$ & $\nearrow[17]$ & $\searrow[17]$ \\
\hline Penetration & $\searrow[7]$ & $\nearrow[18]$ & $\searrow[19]$ \\
\hline Dilution & $\nearrow[15]$ & $\nearrow[16,18]$ & $\searrow[17]$ \\
\hline Melt rate & $-[20]$ & $\nearrow[20]$ & $-[20]$ \\
\hline Risk of arc blow & $\nearrow[3]$ & - & $\nearrow[19]$ \\
\hline
\end{tabular}

[remark: '-' means no visible influence is found]

Raising the arc voltage will result in a decrease of toughness, reflected by the Charpy impact energy [15]. Increasing the welding speed can cause porosities and a non uniform weld bead shape [16, 19]. At the same time the cooling rate will be higher.

\subsection{Fixed parameters}

In the setup, some parameters have a fixed value, for instance the polarity of the wire electrodes which is determined by the power sources.

Stick out length is defined as the length between the wire electrode tip and the workpiece. It is a variable which is chosen by a rule of thumb declaring that the stick out should be eight times the wire diameter [18]. The wire electrode diameter is $4 \mathrm{~mm}$, so the stick out length is set at $32 \mathrm{~mm}$.

The wire grade and flux type are coupled and depend on the base material (S235). Different combinations of wire grade and flux type cause another melting behaviour and chemical reactions. In the planned test, the combination of the following ESAB materials will be used: OK Flux 10.62 and wire grade Autorod 12.24 [21]. In Table 3 an overview is given of the properties of the weld metal.

Table 3: Typical weld metal chemical composition and mechanical properties [21]

\begin{tabular}{|c|c|c|c|c|c|c|c|}
\hline \multicolumn{4}{|c|}{ Chemical composition (\%) } & \multicolumn{4}{c|}{ Weld metal mechanical properties } \\
\hline C & Si & Mn & Mo & $\begin{array}{c}\mathrm{R}_{0,2} \\
(\mathrm{MPa})\end{array}$ & $\begin{array}{c}\mathrm{R}_{\mathrm{m}} \\
(\mathrm{MPa})\end{array}$ & $\begin{array}{c}\mathrm{CVN} \text { at } \\
-40^{\circ} \mathrm{C}(\mathrm{J})\end{array}$ & $\begin{array}{c}\mathrm{CVN} \text { at } \\
-50^{\circ} \mathrm{C}(\mathrm{J})\end{array}$ \\
\hline 0,07 & 0,2 & 1,0 & 0,5 & 500 & 580 & 60 & 45 \\
\hline
\end{tabular}


In Figure 3 and Table 4 the dimensional parameters for I- and X-preparation are compared.

\section{1 l-groove}

In this type of weld bevel preparation, the two surfaces of the plates are combined and aligned along their length and height. The root gap is minimized. The top sides can be chamfered to a maximum depth of $3 \mathrm{~mm}$. This results in a deeper penetration, less faults and better weld bead surface.

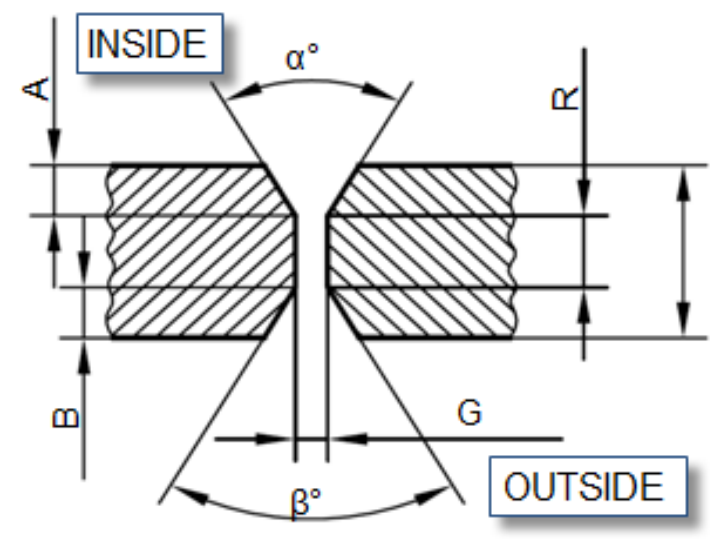

Figure 3: Weld bevel preparation [9]

The use of I-preparation is limited by the risk of burn through, for smaller thicknesses. It is also limited for thicker plates, where a too high current is needed for good penetration and where it will cause a too high weld reinforcement.

The advantages of this preparation are the need for less wire electrode material and a bigger dilution.

Table 4: Plate preparation [3, 9]

\begin{tabular}{|c|c|c|c|c|c|}
\hline Preparation & $\begin{array}{c}\text { Plate thickness } \\
{[\mathrm{mm}]}\end{array}$ & Root gap G [mm] & $\begin{array}{c}\text { Root face R } \\
{[\mathrm{mm}]}\end{array}$ & $\begin{array}{c}\text { Root opening } \alpha \\
{\left[{ }^{\circ}\right]}\end{array}$ & $\begin{array}{c}\text { Root opening } \beta \\
{\left[{ }^{\circ}\right]}\end{array}$ \\
\hline $\mathrm{I}$ & $6-16$ & $0,2-1,5$ & - & - & - \\
\hline $\mathrm{X}$ & $14-60$ & $\leq 0,8$ & $6-20$ & $40-90$ & $40-90$ \\
\hline
\end{tabular}

\subsection{X-groove}

An X-preparation is defined by two root opening angles, the root face and the position of the root face. An asymmetry in the root angles and position of the root face diminishes the risk for burn through, because the current will be lower for the first weld, which will be welded in the smallest root opening $[6,16]$.

The width of the bead, for an acceptable aspect ratio, will limit the minimum root angle [22]. The aspect ratio is defined by the ratio of height versus width of the weld bead $[8,20]$.

The advantage of this preparation is that less current is required for a good penetration. On the other hand, there will be more difficulties in aligning the plates, more wire electrode material will be needed and a deeper penetration raises the risk of solidification cracks [3].

\section{WELD TRIALS}

There is a certain range of welding parameters which allows to obtain an appropriate weld bead geometry. This range should preferably be applicable for a wide range of different steel grades. S235 steel was chosen in the range of 12,7 to $25 \mathrm{~mm}$ for the first series of weld trials.

Five different plate thicknesses have to be tested, which are representative values for the windmill and piping industry. The length of the test strips is approximately $1,60 \mathrm{~m}$. Furthermore, the machine setup allows welding with up to five wires in tandem. This resulted in a first test matrix, shown in Table 5, which gives an overview on the number of tests to perform.

A second matrix contains the input values of the welding parameters for each of the proposed welding procedures. The input values that can be varied, are welding current, arc voltage, welding speed, stick out, 
angles of the welding wire and the distance between the wires. The values of the input are constrained by the total heat input, which should be lower or equal to $3,5 \mathrm{~kJ} / \mathrm{mm}$.

Based on literature and preliminary tests of OCAS and ESAB, the initial input values were obtained. By testing and metallographic investigation of the weld, these preliminary values will be adjusted to optimize the welding process.

Table 5: Testmatrix

\begin{tabular}{|c|c|c|c|c|c|c|}
\hline \multirow{2}{*}{$\begin{array}{c}\text { Number } \\
\text { of wires }\end{array}$} & \multicolumn{5}{|c|}{ Plate thickness ( mm ) } \\
\cline { 3 - 7 } & 12,7 & 15 & 18 & 20 & 25 \\
\hline 1ID & 1OD & 1 & 2 & 3 & 4 & - \\
\hline 2ID & 1OD & 5 & 6 & 7 & 8 & 9 \\
\hline 2ID & $2 \mathrm{OD}$ & 10 & 11 & 12 & 13 & 14 \\
\hline 3ID & 2OD & 15 & 16 & 17 & 18 & 19 \\
\hline 3ID & $3 \mathrm{OD}$ & 20 & 21 & 22 & 23 & 24 \\
\hline 4ID & $3 \mathrm{OD}$ & 25 & 26 & 27 & 28 & 29 \\
\hline 4ID & 4OD & 30 & 31 & 32 & 33 & 34 \\
\hline 3ID & $5 \mathrm{OD}$ & 35 & 36 & 37 & 38 & 39 \\
\hline 4ID & 5OD & 40 & 41 & 42 & 43 & 44 \\
\hline
\end{tabular}

$\mathrm{ID}=$ inner diameter; $\mathrm{OD}=$ outer diameter

\section{CONCLUSIONS}

The influences of the welding parameters on the heat input, penetration, excess material, width of the bead, melt rate and dilution were determined by studying literature. Their range for use with an I- and X-groovepreparation are determined for each plate thickness. A matrix for practical weld trials is composed. Evaluation of weld bead geometry an metallographic inspection will be used to determine the range of welding parameters for the different welding procedures.

\section{REFERENCES}

1. aachen, ISF. Chapter 3: Submerged arc welding. 2005 [cited 20119 oktober]; Available from: http://mercury.kau.ac.kr/welding.

2. $\quad$ Miller, Electric Mfg co, Submerged Arc Welding. 1982.

3. $\quad$ Pors, W. Onder poeder lassen. 2008; Available from: www.multiweld.com.

4. J.E.R. Dhas, S. Kumanan, Optimization of parameters of submerged arc weld using non conventional techniques. Applied soft computing, 2011.

5. B.K. Srivastava, S.P. Tewari, J. Prakash, A review on effect of arc welding parameters on mechanical behaviour on ferrous metals/alloys. International journal of engineering science and technology, 2010. 2(5): p. 1425-1432.

6. $\quad \mathrm{ESAB}$, Submerged arc welding. 2008.

7. Dhooge, A., Cursus metaalconstructies - constructietechnieken. 2010.

8. M.E. Khallaf, M.A. Ibrahim, N.A. El-Mahallawy, M.A. Taha, On crack susceptibility in the submerged arc welding of medium-carbon steel plates. Journal of materials processing technology, 1995. 68: p. 43-49.

9. $\quad$ Depessemier, J.-P., Cursus onder poederdek lassen. 2008: p. 133.

10. K.P. Kolhe, C.K. Datta, Prediction of microstructure and mechanical properties of multipass SAW. Journal of materials processing technology, 2008. 197: p. 241-249.

11. Kobelco. STP\&I Constructs "The Symbolic Middle East Bridge" in The Kingdom of Thailand. Kobelco Welding Today 19998 november 2011]; Available from: http://www.kobelcowelding.com.

12. S. Moeinifar, A.H. Kokabi, H.R.M. Hosseini, Role of tandem submerged arc welding thermal cycles on properties of the heat affected zone in X80 microalloyed pipe line steel. Journal of materials processing technology, 2011. 211: p. 368-375.

13. V. Gunaraj, N. Murugan, Prediction of heat-affected zone characteristics in submerged arc welding of structural steel pipes. Welding Research, 2002: p. 94-102.

14. Lincoln. Prevent arc blow when welding. 2001 [cited 2011 Oktober]; Available from: www. metalforming.com.

15. S. Datta, M. Sundar, A. Bandyopadhyay, G. Nandi, P.K. Pal, S.C. Roy. Effect of electrode stick out on quality and performance of submerged arc weldment-experimental and statistical analysis. in International conference on mechanical engineering. 2005. Bangladesh. 
16. P. Kanjilal, T.K. Pal, S.K. Majumdar, Combined effect of flux and welding parameters on chemical composition and mechanical properties of submerged arc weld metal. Journal of materials processing technology, 2006. 171: p. 223-231.

17. Van_Caenegem, N., Cursus lasmetalurgie. 2010.

18. NIL, Apparatuur voor het onderpoeder lassen. Laskennis opgefrist, 2008. 16.

19. K. Prasad, D.K. Dwivedi, Some investigations on microstructure and mechanical properties of submerged arc welded HSLA steel joints. The international journal of advanced manufacturing technology, 2008. 36: p. 475-483.

20. R.S. Chandel, H.P. Seow, F.L. Cheong, Effect of increasing deposition rate on the bead geometry of submerged arc welds. Journal of materials processing technology, 1997. 74: p. 124-128.

21. ESAB, Technical handbook, in Submerged arc welding. 2008.

22. K. Şirin, S.Y. Şirin, E. Kaluç. A computer program for choosing welding parameters in spirally welded pipe production. in 13 th International Conferance on Computer Technology in Welding. 2003. Florida-USA: American Welding Society (AWS). 